\title{
A low-frequency ice-penetrating radar system adapted for use from an airplane: test results from Bering and Malaspina Glaciers, Alaska, USA
}

\author{
Howard CONWAY, ${ }^{1}$ Ben SMITH, ${ }^{1}$ Pavan VASWANI, ${ }^{1}$ Kenichi MATSUOKA, ${ }^{1}$ \\ Eric RIGNOT, ${ }^{2}$ Paul $\mathrm{CLAUS}^{3}$ \\ ${ }^{1}$ Department of Earth and Space Sciences, University of Washington, Box 351310, Seattle, WA 98195-1310, USA \\ E-mail: conway@ess.washington.edu \\ ${ }^{2}$ Department of Earth System Science, University of California-Irvine, Croul Hall, Irvine, CA 92697-3100, USA \\ ${ }^{3}$ Ultima Thule Lodge, PO Box 109, Chitina, AK 99501, USA
}

\begin{abstract}
Ice-thickness measurements are needed to calculate fluxes through fast-flowing outlet glaciers in Greenland, Alaska, Patagonia and Antarctica. However, relatively high attenuation of radio waves by dielectric absorption and volume scattering from englacial water hampers detection of the bed through warm deep ice. In the past we have had success measuring ice thickness of temperate glaciers using a ground-based monopulse radar system operating at low frequencies $(2 \mathrm{MHz})$. Here we adapt the same system to operate from an airplane. Test flights over Bering Glacier, Alaska, USA, detected the bed through ice up to $1250 \mathrm{~m}$ thick. Flights across the Seward-Malaspina Glacier system, Alaska, resolved the ice thickness of Malaspina Glacier, but strong hyperbolic-shaped returns obscured the bed echo through the Seward throat. It is likely that this clutter in the signal was caused by off-nadir returns from chaotic surface crevasses that are ubiquitous in the throat region.
\end{abstract}

\section{INTRODUCTION}

Recent observations of remarkable changes in flow of outlet glaciers in Greenland (e.g. Howat and others, 2007), Alaska (e.g. Meier and others, 2007), Patagonia (e.g. Rignot and others, 2003) and Antarctica (e.g. Rignot and others, 2008) all indicate that dynamical responses to warming contribute significantly to the mass imbalance of glacier systems and ice sheets. Modelers are now seeking to include these responses but model development and validation is hampered by a lack of ice-thickness data for many of these outlet glaciers. Ice-thickness measurements (combined with surface velocities) are fundamental for estimating the ice flux. Basal conditions (e.g. bed roughness, wet/frozen bed) also exert strong control on glacier dynamics.

Radio-echo sounding methods are well proven for mapping ice thickness, internal structures and basal conditions of glaciers and ice sheets (Bogorodsky and others, 1985). Power received from reflectors, such as internal layers and the ice-bed interface, depends on the characteristics of the radar system (wavelength $\lambda$, transmitted power $P_{\mathrm{t}}$, antenna gain $G$ ), as well as the properties of the reflecting layer and the overlying ice. For a radar reflector with Fresnel reflectivity $R$ at depth $x$, the received power can be written:

$$
P_{\mathrm{r}}=\frac{P_{\mathrm{t}} G^{2} \lambda^{2} R L_{(x)}}{64 \pi^{3} x^{2}}
$$

Equation (1) includes terms to account for losses associated with geometric spreading $\left(1 / 4 \pi x^{2}\right)$, and losses, $L_{(x)}$, that include surface transmission losses, dielectric absorption during the two-way travel, and scattering from structures such as surface crevasses and englacial inclusions of liquid water. Losses from dielectric absorption, $L_{\mathrm{d}(x)}$, depend on the dielectric conductivity $\sigma$ and permittivity $\varepsilon$ of the ice column (Cheng, 1989):

$$
L_{\mathrm{d}(x)}=\exp \left(-4.343 \sqrt{\frac{\mu_{0}}{\varepsilon_{0}}} \frac{\sigma}{\sqrt{\varepsilon}} x\right),
$$

where $\mu_{0}$ and $\varepsilon_{0}$ are the magnetic permeability and permittivity of a vacuum. Laboratory measurements of $\sigma$ and $\varepsilon$ for pure ice indicate that $L_{\mathrm{d}(x)}$ has a strong temperature dependence: $5.4 \mathrm{~dB} \mathrm{~km}^{-1}$ at $-20^{\circ} \mathrm{C}, 8.8 \mathrm{~dB} \mathrm{~km}^{-1}$ at $-15^{\circ} \mathrm{C}$, $14 \mathrm{~dB} \mathrm{~km}^{-1}$ at $-10^{\circ} \mathrm{C}$ (Matsuoka and others, 1996) and $31 \mathrm{~dB} \mathrm{~km}^{-1}$ at $-5^{\circ} \mathrm{C}$ (Matzler and Wegmuller, 1987). Laboratory data are not yet available for ice warmer than $-5^{\circ} \mathrm{C}$, but the data show a clear trend of increasing losses near the melting point. Absorption also increases with impurities, but with less sensitivity than with temperature (MacGregor and others, 2007).

Losses from volume scattering can be substantial in temperate glaciers where crevasses and englacial water channels are common (Smith and Evans, 1972; Arcone, 2002). Rayleigh scattering theory suggests that when the scatterers are smaller than the radar wavelength $\lambda$, scattering losses are inversely proportional to $\lambda^{4}$ (Ishimaru, 1978). This dependence, combined with the radar equation (Equation (1)) that indicates received power should increase with $\lambda^{2}$, suggests that bed detection should improve at low frequencies. We have had good success imaging basal topography of temperate glaciers using our ground-based low-frequency $(1-5 \mathrm{MHz})$ monopulse radar system: Black Rapids Glacier in Alaska, for example, was found to be up to $630 \mathrm{~m}$ thick (Gades, 1998); Glaciar Tyndall in Patagonia is up to $740 \mathrm{~m}$ thick (Raymond and others, 2005). However surface crevasses and meltwater streams often impede travel across the surface of many of these glaciers; mapping the thickness of large outlet glaciers from the surface is often logistically problematic. For this reason, here we adapt our ground-based system to operate from an airplane.

\section{METHODS}

Our monopulse radar system is similar to that described by Watts and Wright (1981). Stability of the transmitted power is improved over the earlier design by the use of MOSFETs 


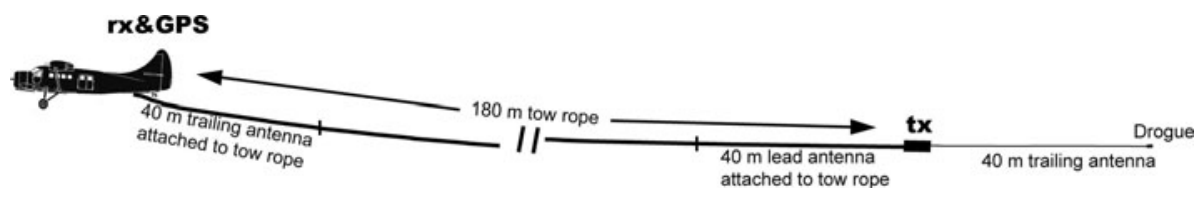

Fig. 1. Configuration used for airborne radio-echo sounding tests with $2 \mathrm{MHz}$ monopulse system. The receiver (rx) and GPS were on board the airplane. The transmitter and power supply (a $7 \mathrm{Ah}, 12 \mathrm{~V}$ battery) (tx) were placed in a cardboard tube (total weight of $5 \mathrm{~kg}$ ) and deployed through a hatch in the rear fuselage after take-off and retrieved prior to landing. A drogue (a small plastic funnel) was attached to the end of the trailing leg of the transmit antenna. For this work we connected a full half-wavelength dipole antenna to the transmitter, and a single quarter-wave antenna to the receiver (i.e. no leading leg connected to the receiver). The leading half of the transmit antenna and the trailing receive antenna were attached to the tow rope with tape. Spacing between the transmitter and receiver was $180 \mathrm{~m}$.

(metal oxide semiconductor field effect transistors) instead of avalanche-transistor switches (Weertman, 1993). Our latestgeneration transmitter, which is powered by a $12 \mathrm{~V}$ battery, transmits up to 300 pulses per second. The rise time for each pulse is $15 \mathrm{~ns}$, and the amplitude is $\pm 2000 \mathrm{~V}$. Since the transmitter generates a short pulse with a broad frequency spectrum, the center frequency depends on the characteristics of the transmit antenna (Weertman, 1993; Gades, 1998). The antenna typically used for a monopulse system is a resistively loaded half-wavelength center-fed dipole; each leg of the dipole is one-quarter wavelength; for an airborne $2 \mathrm{MHz}$ antenna, each leg is about $40 \mathrm{~m}$.

Our latest-generation receiver (a National Instruments PXI-5122 digitizer) can acquire and average more than 1000 waveforms per second at up to $100 \mathrm{MHz}$ sampling (10 ns digitizing intervals for the waveform) with 14-bit voltage digitization. With this system, data acquisition rate is limited by the transmitter repetition rate $(300 \mathrm{~Hz}) .14$-bit digitizing allows us to record concurrently entire waveforms without saturation and small voltage amplitudes associated with weak echoes. A laptop computer is used to control the receiver. The output from the receive antenna is connected to a radio-frequency transformer (a balun) and then through a pre-amplifier (Mini-Circuits ZFL-500LN) to the digitizer.

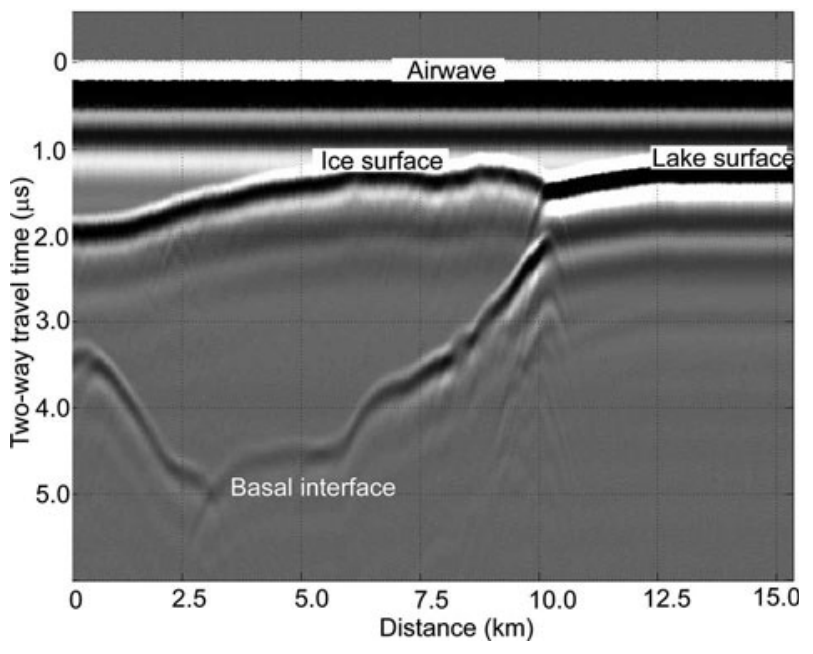

Fig. 2. $2 \mathrm{MHz}$ profile across the terminus of Bering Glacier. The $y$ axis is two-way travel time recorded by the receiver. Time zero is the time of the first arrival of the airwave from the transmitter $180 \mathrm{~m}$ behind the airplane. This longitudinal profile starts up-glacier and crosses the terminus onto Vitus Lake at $\mathrm{km} \mathrm{10.} \mathrm{The} \mathrm{first} \mathrm{reflection} \mathrm{is}$ from the surface and the second is from the bed. Maximum ice thickness (at $\mathrm{km} 2.7$ ) is $306 \pm 7 \mathrm{~m}$.
Our system is lightweight $(15 \mathrm{~kg})$, low-power and low-cost ( US\$20000).

The long antennae needed for low-frequency monopulsed systems are not well suited for airborne work, but following pioneering work by Watts and Wright (1981) we adapted our system to operate from an airplane. For groundbased profiling we typically operate 'end-fire parallel'. That is, the receiver and transmitter are towed in-line behind a snow machine and the transmit and receive antennae are also in-line (Gades, 1998). Fulfilling the need to have the receiver on board the airplane precludes deploying the leading leg of a half-wavelength receive dipole. Experiments on the ground with different antenna configurations indicate: power received degraded significantly when the transmitter was operated without a full half-wavelength dipole antenna; in contrast, power received decreased by only $\sim 4 \%$ when the leading leg of the receive dipole was disconnected. Hence, for airborne work, we connected a full half-wavelength dipole to the transmitter, and a single quarter-wave antenna to the receiver.

Figure 1 shows the configuration used for airborne profiling. For these experiments, we used a DHC-3 (de Havilland single-engine Otter) airplane operated by one of us (P.C.) out of Ultima Thule, Alaska. The airplane was located using the global positioning system (GPS). The receiver was kept on board the airplane and we deployed the transmitter through a port in the floor of the rear fuselage after take-off. Spacing between the transmitter and receiver was $180 \mathrm{~m}$. We retrieved the transmitter before landing. During profiling, the height of the airplane above the surface varied from about 100 to $150 \mathrm{~m}$. Ground speed was typically $\sim 40 \mathrm{~m} \mathrm{~s}^{-1}$.

\section{ICE-THICKNESS MEASUREMENTS}

Figure 2 shows results from a test profile flown across the terminus of Bering Glacier, Alaska, USA, in July 2005. In this profile, individual waveforms were recorded, but generally we stack (average) 16 waveforms to reduce system and environmental noise. Additional processing includes bandpass filtering, geolocating the waveforms using GPS, and converting two-way travel time to surface elevation and ice thickness. Two-way travel time is converted to distance by assuming a wave speed of $168.5 \mathrm{~m} \mathrm{\mu s}^{-1}$ in ice (Glen and Paren, 1975). This assumption will underestimate ice thickness for snow-covered regions of the glacier because the wave speed is faster through snow and firn, and will overestimate ice thickness in regions of the glacier that contain a large amount of liquid water (Macheret and others, 1993). The resolution ( $1 / 4$ wavelength) when using $2 \mathrm{MHz}$ antenna is approximately $\pm 40 \mathrm{~m}$ in air and $\pm 20 \mathrm{~m}$ in ice. 


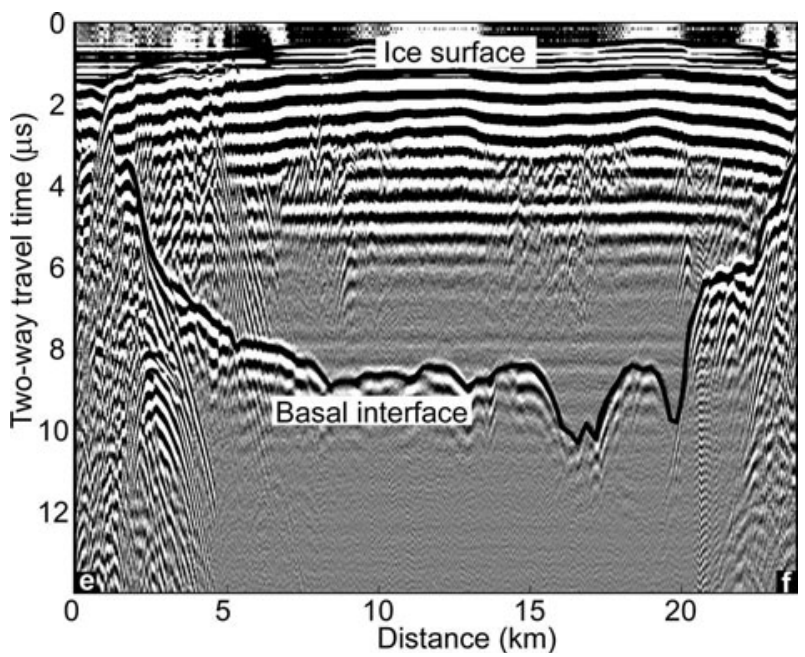

Fig. 3. Cross-section across the trunk of Bering Glacier. The $y$ axis is two-way travel time recorded by the receiver. Maximum ice thickness (at $\mathrm{km} \mathrm{16.5)}$ ) is $760 \pm 12 \mathrm{~m}$. Cross-section end points $\left(\mathrm{A}-\mathrm{A}^{\prime}\right)$ shown in Figure 4.

Uncertainty in the estimate of ice thickness comes primarily from uncertainty in the wave speed (about $\pm 2 \mathrm{~m} \mathrm{ss}^{-1}$, which corresponds to $\pm 1.2 \%$ of the ice thickness) and also from picking the travel time to the surface and to the bed $( \pm 0.01 \mu \mathrm{s}$, which corresponds to $\pm 3 \mathrm{~m}$ ). In this profile, the maximum ice thickness (at km 2.7) is $306 \mathrm{~m}$ with uncertainty $\pm 7 \mathrm{~m}$.

Results shown in Figure 2 were collected with a single quarter-wave antenna connected to the receiver. Figure 3 shows a profile acquired in March 2006 across the trunk region of Bering Glacier. For this profile, the other input to the receiver was connected to the fuselage of the airplane.
This configuration increased ringing of the system (cf. results shown in Fig. 2), but power received from the bed also increased. More tests with different configurations are planned to optimize the system. In this profile, the maximum ice thickness (at $\mathrm{km} \mathrm{16.5)}$ is $760 \mathrm{~m}$ with uncertainty $\pm 12 \mathrm{~m}$.

We estimate the surface elevation of the glacier by subtracting the radar-detected distance to the surface (calculated by assuming a wave speed of $300 \mathrm{~m} \mathrm{ss}^{-1}$ in air and with geometric corrections for the distance between the transmitter and the receiver) from the GPS-measured altitude of the airplane. As well as uncertainty in the wave speed, additional uncertainty arises because the elevation difference between the GPS on the airplane and the center point of the transmitter-receiver system $(\sim 25 \mathrm{~m})$ is not always constant. Operating the radar system together with a laser profiler would provide a more accurate geolocated map of surface and bed topography. Figure 4 shows a compilation of surface and bed elevations measured along flight-lines over Bering Glacier in March 2006. Maximum ice thickness measured with the system was $1250 \mathrm{~m}$; at greater depths in the upper glacier and the Bagley Ice Field the bed reflection faded into the noise. Agreement of ice-thickness measurements at the five crossover locations was between 3 and $41 \mathrm{~m}$, the latter being in an area of steep bed-topography gradients.

Figure 5 shows flight-lines and surface and bed elevations over Malaspina Glacier, Alaska, also in March 2006. In the Seward throat (the region $\sim 60.15^{\circ} \mathrm{N},-140.4^{\circ} \mathrm{E}$ that separates Malaspina and Seward Glaciers; Fig. 5), strong hyperbolic-shaped returns obscured the bed return (along section $a-b)$, so the bed could not be identified reliably. The hyperbolae are likely caused by off-nadir returns from chaotic surface crevasses that are widespread through the Seward throat.

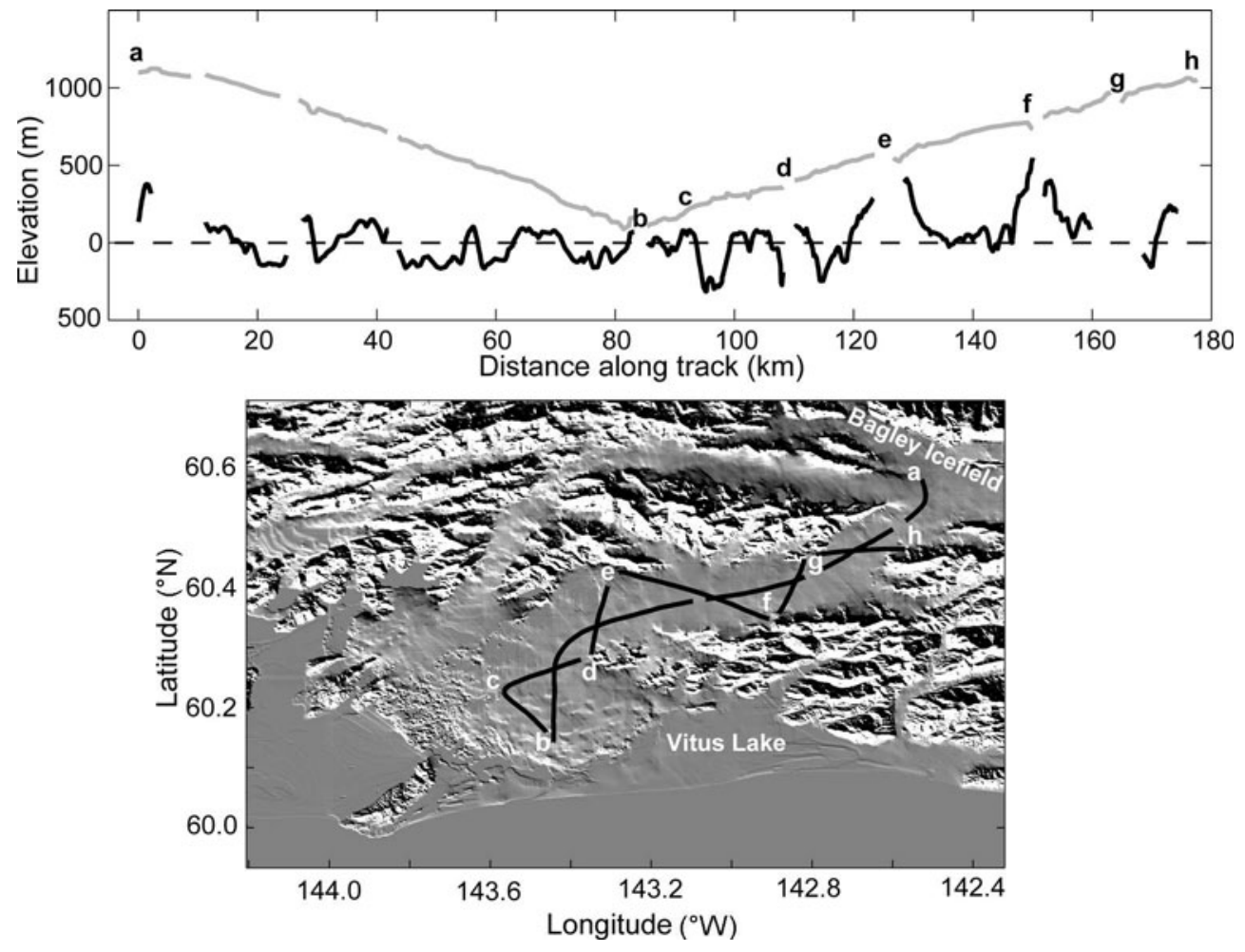

Fig. 4. Flight-lines with estimates of surface and bed elevations over Bering Glacier, overlain on shaded-relief map (based on National Elevation Dataset, US Geological Survey (USGS) seamless data server, data as of 2002). 


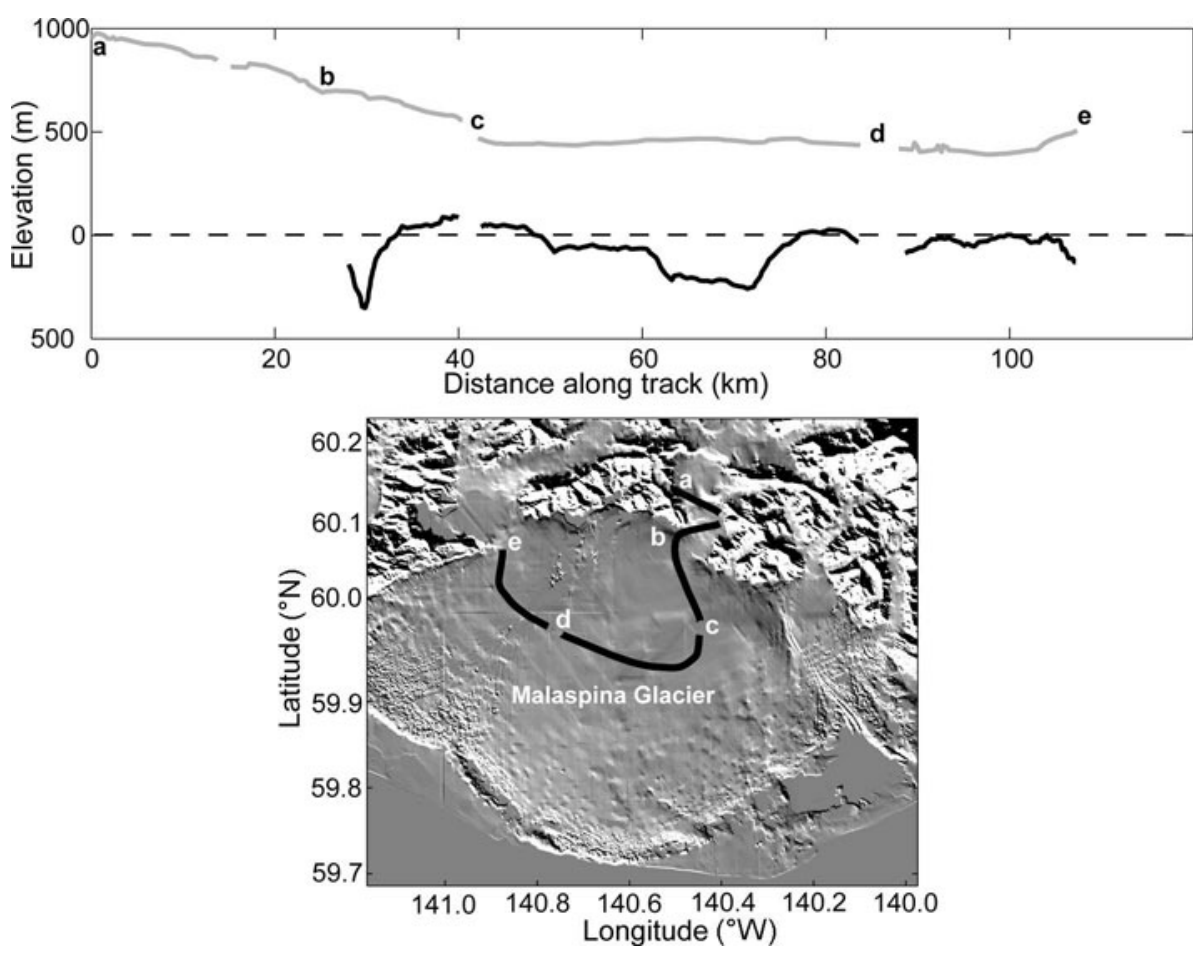

Fig. 5. Flight-lines with estimates of surface and bed elevations over Malaspina Glacier, overlain on shaded-relief map (based on National Elevation Dataset, USGS seamless data server, data as of 2002).

\section{CONCLUSIONS}

We successfully adapted our $2 \mathrm{MHz}$ monopulse radar system to operate on board an airplane. Using this simple low-cost system, we detected the bed through temperate ice up to $1250 \mathrm{~m}$ thick. We have not yet made a direct comparison of airborne and ground-based measurements, but our first impression is that the airborne data are comparable to or perhaps even better than ground-based data. One possible reason for the improvement is that surface transmission losses are reduced when operating from the air.

The uncertainty in ice thickness for $1200 \mathrm{~m}$ of ice is about $18 \mathrm{~m}$; given other uncertainties (such as estimating the depth-averaged ice velocity from surface measurements), the accuracy is adequate for estimating ice fluxes through outlet glaciers.

We plan several modifications to improve the system: (1) a low-noise balun and pre-amplifier that matches the impedance between the antenna and receiver would improve the signal-noise ratio; (2) additional filtering and signal processing (e.g. matched filtering, slope lateral averaging, and along-track unfocused synthetic aperture radar (SAR) processing) also has the potential to improve the signal-noise ratio and detection of weak bed echoes. Specifically, Legarsky and others (2001) and Peters and others (2005) have demonstrated that coherent processing of radar data is an effective way to raise bed echoes above the noise and clutter. Further, along-track SAR processing is now a wellestablished method for eliminating unwanted ray paths and to reduce the volume that contributes to the clutter (e.g. Gogineni and others, 1998; Moran and others, 2000). Offtrack reflections can also be problematic, especially when sounding narrow steep-walled outlet glaciers. Ambiguities can be reduced by two-pass migration of radar profiles, but this requires a dense grid of intersecting profiles (Welch and others, 1998). An alternative approach that has been used successfully on Mars is to subtract the observed reflections from reflections expected based on a high-resolution model of surface topography (personal communication from A. Safaeinili, 2006; Plaut and others, 2007).

\section{ACKNOWLEDGEMENTS}

This work was partially funded by the US National Science Foundation (NSF; EAR0409884 and ARC-0732739) and NASA (contract 1267029). Development of the software for the system was done primarily by P.V. as a summer research project, which was jointly supported by the University of Washington Space Grant and NSF ANT-0440847. We thank M. Truffer and B. Hallet for their field assistance and enthusiasm. We thank J. Chin, M. McCarthy and F. Weller for their innovative design and construction of the University of Washington transmitters. We also thank F. Pattyn (scientific editor) and reviewers D. Vaughan and A. Rivera for constructive comments that helped improve the manuscript.

\section{REFERENCES}

Arcone, S.A. 2002. Airborne-radar stratigraphy and electrical structure of temperate firn: Bagley Ice Field, Alaska, USA. J. Glaciol., 48(161), 317-334.

Bogorodsky, V.V., C.R. Bentley and P.E. Gudmandsen. 1985. Radioglaciology. Dordrecht, etc., D. Reidel Publishing Co.

Cheng, D.K. 1989. Field and wave electromagnetics. Second edition. Reading, MA, Addison-Wesley.

Gades, A.M. 1998. Spatial and temporal variations of basal conditions beneath glaciers and ice sheets inferred from radio echo soundings. (PhD thesis, University of Washington.)

Glen, J.W. and J.G. Paren. 1975. The electrical properties of snow and ice. J. Glaciol., 15(73), 15-38.

Gogineni, S., T. Chuah, C. Allen, K. Jezek and R.K. Moore. 1998. An improved coherent radar depth sounder. J. Glaciol., 44(148), 659-669. 
Howat, I.M., I.R. Joughin and T.A. Scambos. 2007. Rapid changes in ice discharge from Greenland outlet glaciers. Science, 315(5818), 1559-1561.

Ishimaru, A. 1978. Wave propagation and scattering in random media. New York, Academic Press.

Legarsky, J.J., P. Gogineni and T.L. Atkins. 2001. Focused syntheticaperture radar processing of ice-sounder data collected over the Greenland ice sheet. IEEE Trans. Geosci. Remote Sens., 39(10), 2109-2117.

MacGregor, J.A., D.P. Winebrenner, H. Conway, K. Matsuoka, P.A. Mayewski and G.D. Clow. 2007. Modeling englacial radar attenuation at Siple Dome, West Antarctica, using ice chemistry and temperature data. J. Geophys. Res., 112(F3), F03008. (10.1029/2006JF000717.)

Macheret, Yu.Ya., M.Yu. Moskalevsky and E.V. Vasilenko. 1993. Velocity of radio waves in glaciers as an indicator of their hydrothermal state, structure and regime. J. Glaciol., 39(132), 373-384.

Matsuoka, T., S. Fujita and S.J. Mae. 1996. Effect of temperature on dielectric properties of ice in the range 5-39 GHz. J. Appl. Phys., 80(10), 5884-5890.

Matzler, C. and U. Wegmuller. 1987. Dielectric properties of freshwater ice at microwave frequencies. J. Phys. D, 20(12), 1623-1630.

Meier, M.F. and 7 others. 2007. Glaciers dominate eustatic sealevel rise in the 21st century. Science, 317(5841), 1064-1067.

Moran, M.L., R.J. Greenfield, S.A. Arcone and A.J. Delaney. 2000. Multidimensional GPR array processing using Kirchhoff migration. J. Appl. Geophys., 43(2-4), 281-295.
Peters, M.E., D.D. Blankenship and D.L. Morse. 2005. Analysis techniques for coherent airborne radar sounding: application to West Antarctic ice streams. J. Geophys. Res., 110(B6), B06303. (10.1029/2004JB003222.)

Plaut, J.J. and 23 others. 2007. Subsurface radar sounding of the South Polar layered deposits of Mars. Science, 316(5821), 92-95.

Raymond, C.F., T.A. Neumann, E. Rignot, K. Echelmeyer, A. Rivera and G. Casassa. 2005. Retreat of Glaciar Tyndall, Patagonia, over the last half-century. J. Glaciol., 51(173), 239-247.

Rignot, E., A. Rivera and G. Casassa. 2003. Contribution of the Patagonian icefields of South America to sea level rise. Science, 302(5644), 434-437.

Rignot, E. and 6 others. 2008. Recent Antarctic ice mass loss from radar interferometry and regional climate modelling. Nature Geosci., 1(2), 106-110.

Smith, B.M.E. and S. Evans. 1972. Radio echo sounding: absorption and scattering by water inclusion and ice lenses. J. Glaciol., 11(61), 133-146.

Watts, R.D. and D.L. Wright. 1981. Systems for measuring thickness of temperate and polar ice from the ground or from the air. J. Glaciol., 27(97), 459-469.

Weertman, B.R. 1993. Interpretation of ice sheet stratigraphy: a radio-echo sounding study of the Dyer Plateau, Antarctica. (PhD thesis, University of Washington.)

Welch, B.C., W.T. Pfeffer, J.T. Harper and N.F. Humphrey. 1998. Mapping subglacial surfaces of temperate valley glaciers by twopass migration of a radio-echo sounding survey. J. Glaciol., 44(146), 164-170. 